\title{
Continuous renal replacement therapy for safe and adequate voriconazole intravenous treatment: enough reason to be confident?
}

\author{
Patrick M Honore, Rita Jacobs, Inne Hendrickx, Elisabeth De Waele, Viola Van Gorp and Herbert D Spapen \\ See related research by Kiser et al., http://ccforum.com/content/19/1/32
}

Voriconazole is a first-line agent for treatment of systemic mycotic infections. However, intravenous use is contraindicated in patients with creatinine clearance $<50 \mathrm{ml} /$ minute because of accumulation of the toxic vehicle sulfobutyletherbeta-cyclodextrin sodium $[1,2]$. In a recent issue of Critical Care, Kiser and colleagues furnished convincing pharmacological evidence that sulfobutylether-beta-cyclodextrin sodium but not voriconazole was effectively removed by continuous veno-venous hemofiltration $(\mathrm{CVVH})$. They concluded that standard intravenous voriconazole doses could be safely used when patients were placed under continuous renal replacement therapy [3].

We acknowledge the clinical relevance of this study but advocate a more balanced appraisal of the results. First, Kiser and colleagues applied CVVH doses ranging from approximately 25 to $75 \mathrm{ml} / \mathrm{kg} /$ hour in a small group of patients. This approach might introduce significant difference in substance elimination and does not conform to routinely used CVVH doses. Second, the study showed that sulfobutylether-beta-cyclodextrin sodium, being a middle molecular weight substance, was highly and dosedependently eliminated by convection. However, diffusionbased continuous renal replacement therapy arguably will produce equally effective elimination. Third, if $\mathrm{CVVH}$ is performed without high flux or high cutoff membranes, convective capacity may rapidly falter due to a decrease in membrane porosity. This can be avoided by using regional citrate anticoagulation, which was not applied in this study.

Therefore, we recommend using CVVH (to privilege convective drug elimination) at a dose of $35 \mathrm{ml} / \mathrm{kg} / \mathrm{hour}$ (to assure a minimal delivered dose of $25 \mathrm{ml} / \mathrm{kg} /$ hour) under regional citrate anticoagulation (to consolidate filter function) for permitting safe and adequate intravenous voriconazole treatment.

\section{Abbreviations}

CWH: continuous veno-venous hemofiltration.

\section{Competing interests}

The authors declare that they have no competing interests.

\section{Authors' contributions}

$\mathrm{PMH}$ and HDS designed the paper. All authors participated in writing the paper. All authors read and approved the final manuscript.

Published online: 27 May 2015

\section{References}

1. von Mach MA, Burhenne J, Weilemann LS. Accumulation of the solvent vehicle sulphobutylether beta cyclodextrin sodium in critically ill patients treated with intravenous voriconazole under renal replacement therapy. BMC Clin Pharmacol. 2006;6:6.

2. Luke DR, Tomaszewski K, Damle B, Schlamm HT. Review of the basic and clinical pharmacology of sulfobutylether-beta-cyclodextrin (SBECD). J Pharm Sci. 2010;99:3291-301.

3. Kiser $T H$, Fish DN, Aquilante $C L$, Rower JE, Wempe MF, MacLaren $\mathrm{R}$, et al. Evaluation of sulfobutylether- $\beta$-cyclodextrin (SBECD) accumulation and voriconazole pharmacokinetics in critically ill patients undergoing continuous renal replacement therapy. Crit Care. 2015;19:32.

\footnotetext{
* Correspondence: Patrick.Honnore@az.vub.ac.be

ICU Department, Universitair Ziekenhuis Brussel - Vrije Universiteit Brussels,

101 Laarbeeklaan, 1090 Jette, Brussels, Belgium
} 